\title{
Citizens' Evaluation of an Online Argument Visualisation Platform for eParticipation
}

\author{
Eleni Panopoulou, Efpraxia Dalakiouridou, \\ Efthimios Tambouris, and Konstantinos Tarabanis \\ University of Macedonia, Egnatia 156, 54006, Thessaloniki, Greece \\ \{epanopou, eda, tambouris, kat\}@uom.gr
}

\begin{abstract}
Argument visualisation (AV) tools facilitate structured debates utilising elements such as issues, positions and arguments. In this way, AV tools seem promising for improving eParticipation e.g. by avoiding repetition and enhancing clarity in debates. In this paper we present and discuss citizens' opinion on utilising an $\mathrm{AV}$ platform for eParticipation, specifically for discussing the emerging topic of environment and climate change. Results have been interesting; most users found the platform and topic interesting and understandable stating that they would use the platform again in the future and recommend it to other people. However, negative feedback has also been received, mostly in relation to things that frustrated users (e.g. the logic behind $\mathrm{AV}$ ) and suggestions for improvement. As our evaluation is based on a mature AV tool and focuses on general aspects of such tools, we believe that results may be applicable to other AV platforms as well.
\end{abstract}

Keywords: Citizens, climate change, policy making, argument visualisation.

\section{Introduction}

Nowadays, there is an increasing interest by practitioners and researchers regarding open and transparent governance. This is due to recent efforts to cope with current decline in political trust and engagement [1], but also due to the emerging possibilities through the use of modern Web technologies. The European Commission has recognised this urging governments to "use the right tools" in policy making and ensure that "the voices of those affected are being heard" [2]. According to European Commission's 'Smart regulation' mandate [3] stakeholder consultations and impact assessments are viewed as essential parts of the policy making process as it is believed that the policy making process may be improved through the utilisation of evidence-based policy making.

In this context, numerous consultation and deliberation initiatives, also supported by modern Information and Communication Technologies and particularly Web technologies, have recently emerged. Such initiatives mainly aim at informing citizens about policies and consulting them with regards to policy alternatives [4].

However, it has recently been recognised that forum-oriented online deliberation has a number of drawbacks mainly relating to the vast amount of resources needed for 
moderation and for processing debate results (e.g. creating summary reports). Such drawbacks become more evident as online deliberation (e.g. number of posts) increases. However, another family of tools, termed Argument Visualisation (AV) [5] tools (e.g. Debategraph, Cohere [6], AVER [7], Parmenides [8], etc.), seem to offer a new approach to eParticipation debate helping to minimise some of the drawbacks identified in forum-like solutions. The innovation these tools bring to eParticipation is found in the structured way in which deliberation is performed. Instead of unstructured debating (i.e. adding posts of plain text), AV tools only allow contributions through structured well-defined elements such as issues, positions, positive/counter arguments, etc. In this way, people may offer their thoughts in the context of others' opinion, hence avoiding repetition and enhancing clarity, while at the same time facilitating the creation of summary reports. AV tools have started gaining considerable usage but are still not widely used in eParticipation. There is therefore a need for a thorough evaluation of such tools in order to deeper explore their strengths and weaknesses and understand whether they can be widely adopted.

The objective of this paper is to present and discuss citizens' opinion on utilising an AV platform for eParticipation, specifically for discussing the emerging topic of environment and climate change. Through this analysis we aim to understand whether AV tools may be successfully used for eParticipation and under what conditions.

The structure of this paper is as follows. Section 2 shortly presents the AV platform. Section 3 presents the methodology followed for gathering and analysing citizens' feedback. Section 4 presents the gathered results and section 5 provides a detailed discussion of results. Finally, section 6 sums up and concludes this paper.

\section{Argument Visualisation Platform}

WAVE is a Web-based, AV platform developed to facilitate understanding and debating of European legislation. From a technical point of view, WAVE comprises a customised content management system (based on Drupal) which integrates Debategraph, an AV tool developed by Thoughtgraph and provided free as a service to everyone to use or embed in a website. In WAVE, the Drupal interface and Debategraph are integrated, thus enabling data flow between the two sub-systems [9].

The platform operated between December 2009 and January 2011, facilitating debate on climate change at European level but also at national level in France, Lithuania and the UK. Figure 1 displays the platform's home page and Figure 2 an argument map.

A user of the WAVE platform can take advantage of a number of functionalities summarised in three main groups of actions as follows.

1. Explore the map, rate and share ideas. The most important functionality of an AV tool is the ability to explore debates and participate. Through the embedded Debategraph AV tool [9], WAVE enables exploring maps' exploration by clicking on an idea; then, all ideas directly related to the clicked idea are displayed. In this way, visitors can easily transverse from idea to idea throughout the whole map. Debategraph also enables registered users to rank and manage ideas. There is a plethora of idea types available (e.g. issue, 
position, supporting argument, opposing argument, protagonist, etc.) as well as different link types. Adding a new idea involves typing a short description (70 characters maximum) and, if desired, also providing additional details e.g. a larger description (300 characters maximum), text, photos, video (e.g. from YouTube), links etc. Any registered user is able to change any idea on the map. A moderator has been assigned in each map being responsible for editing ideas, deleting irrelevant or offensive contributions, etc.

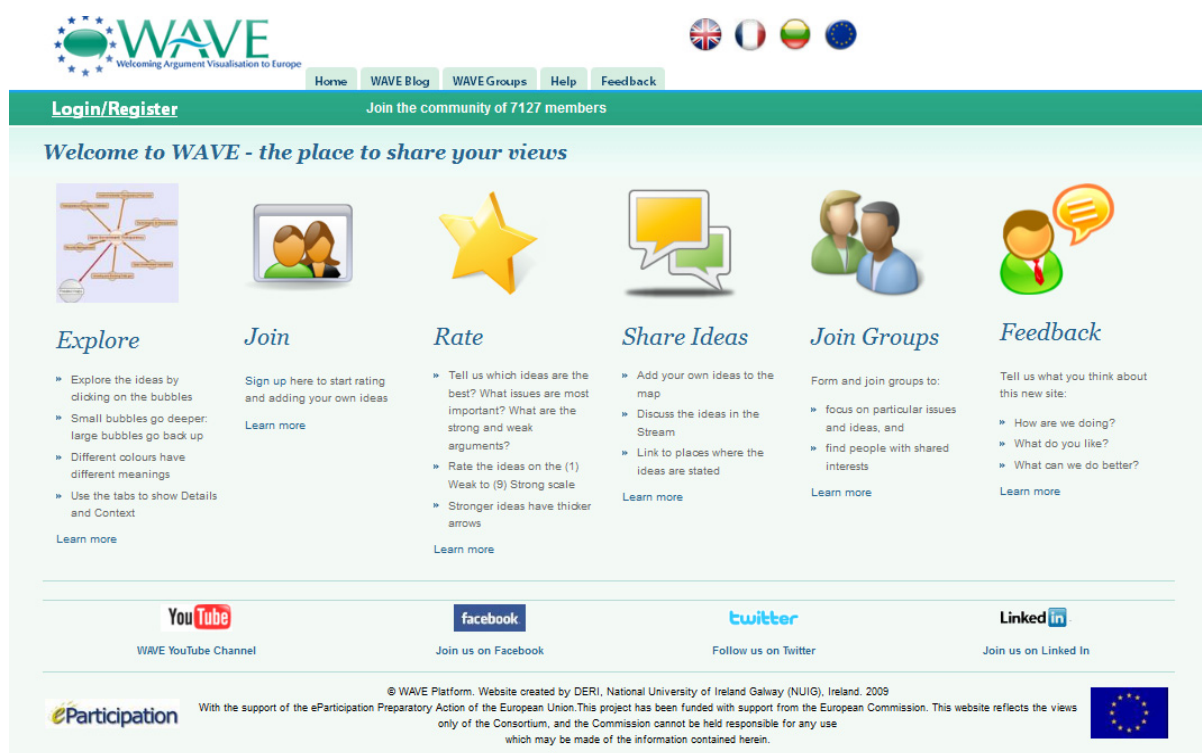

Fig. 1. Platform Home Page (EU pilot)

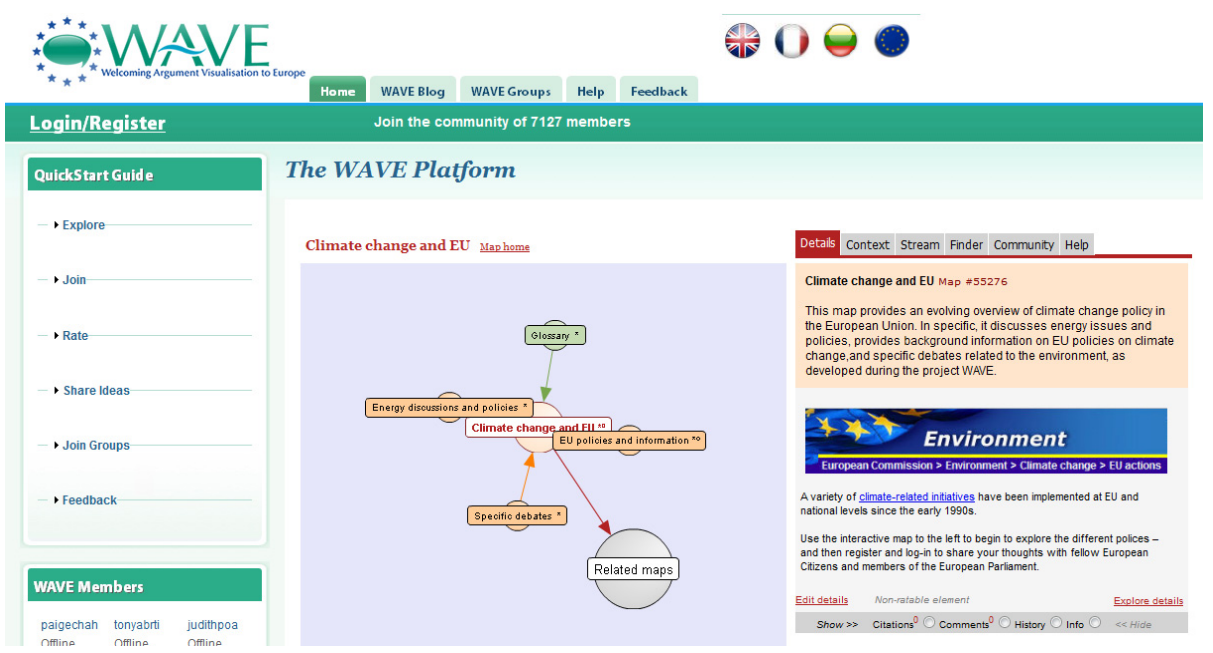

Fig. 2. Exploring an argument map 
2. Create and join groups/invite others. The platform enables registered users to create and manage groups. Each group's home page can embed its own home map which has as the starting point any point of the overall map. The platform also enables writing to blogs, creating events, creating and contributing to polls, and inviting others to groups and maps.

3. Create account, login and provide feedback. Finally, the platform enables registering by simply requiring a valid email address. It also provides an online form for users to evaluate the platform.

\section{Evaluation Methodology}

Evaluation methodologies for electronic participation initiatives have recently emerged in the literature. Most of them are based on Rowe and Frewer's work [10] on participation evaluation and adapt it further to address the "e-" aspect. Most evaluation methodologies have been developed within the context of specific projects, therefore most available frameworks are project-oriented, e.g. [11], [12], [13]. There are, however, a few methodologies that approach eParticipation evaluation from a different aspect, assessing government programmes [14]; specific tools, like e-consultations [15]; or best practice [16]. These methodologies propose evaluation axes, criteria or metrics allocated to measure a number of different perspectives: technical-, social-, process-, democracy-, project- oriented, and they are designed to involve one or more of the following stakeholders: users (targeted groups or the general public), government officials or elected representatives, policy-makers, owners or managing staff of the eParticipation project, experts in the eParticipation field.

The evaluation methodology selected for work presented in this paper is heavily influenced by the methodology created by MOMENTUM project [12], although adapted accordingly. According to the selected methodology for gathering evaluation feedback by citizens an online questionnaire would be used. The questionnaire would be available on the platform making it thus easy for users to contribute. Users from any country are welcome to participate, although it is expected that most of them will come from the three pilot countries, Lithuania, France and UK, as pilots there have produced rich relevant content in their national languages; Lithuanian, French and English.

The questionnaire has been constructed to assess four different axes as follows:

A. Tool and technology axis. It examines AV platform's usability and ease of use.

B. Process axis. It examines AV platform's position in the policy making process.

C. Topic axis. It focuses on the selection of the climate change topic and the potential to use the AV platform for other policy topics.

D. Contact and sustainability axis. It examines users' contact and interaction with the AV platform as well as potential for future use.

Additionally, the questionnaire includes items examining users' demographics for sample profiling purposes. The full user questionnaire is provided in Table 1 below depicting both questionnaire items and pre-defined answers (in italics) where available. It should be noted that all items with pre-defined answers allow only one choice, except from metric 12 which allows choosing one or more answers.

We should note here that Momentum's user evaluation questionnaire proposes the same four axes and is longer than the questionnaire used here. Additionally, most of Momentum's questions have been revised in our questionnaire. We found this 
necessary in order to include specific metrics relevant to our research (e.g. AV tools) while at the same time keeping the overall questionnaire short for users' convenience.

Table 1. User evaluation questionnaire

\begin{tabular}{|c|c|}
\hline Metric & Questionnaire item and possible answers \\
\hline \multicolumn{2}{|r|}{ User characteristics } \\
\hline$M 1$ & Country (Answer given by selecting from a dropdown list) \\
\hline$M 2$ & Gender (Male / Female) \\
\hline M 3 & Age (Under 20/21-30/31-40/41-50/51-60/Over 60) \\
\hline$M 4$ & Education (Primary / Secondary / Higher education) \\
\hline M 5 & $\begin{array}{l}\text { In your job, do you principally: (Select one of the following: Develop } \\
\text { policies / Implement policies / Carry out research or consult policy } \\
\text { makers / Teach or train / Work for the media / Self-employed / Other) }\end{array}$ \\
\hline M 6 & $\begin{array}{l}\text { How experienced are you in using the Internet? (No experience / Basic } \\
\text { skills (internet browsing) / Advanced skills (word processing, } \\
\text { spreadsheets, presentations, databases) / Professional skills (software } \\
\text { developer, systems engineer, network designer, etc.)) }\end{array}$ \\
\hline
\end{tabular}

Tool and technology

\begin{tabular}{l|l}
$M 7$ & Do you think the platform (tools and guidance) provided online is easy
\end{tabular} to use? (Yes, very easy / Yes, fairly easy / No, not that easy / No, very difficult)

M 8 Were there any elements that caused confusion? (Yes / No) If yes, please describe which ones and why (text field)

M9 Considering what you have seen on the web site, what was the best feature? (text field)

M 10 Considering what you have seen on the web site, what was the worst feature? (text field)

\section{Process}

\begin{tabular}{l|l}
$M 11$ & In your view, does the WAVE platform help you better understand the
\end{tabular} issues under discussion? (Yes / No)

M 12 In your view, the WAVE platform mostly helps to: (Select one or more of the following: Understand complex legislation / express opinions / measure public opinion / engage with peers and form communities / increase your participation in the democratic process / allows you to make informed decisions)

M 13 After participating, what kind of feedback would you like to receive from the platform or other users? (text field)

\section{Topic}

M 14 $\quad$ Do you find the climate change topic discussed in the platform appealing and interesting? (Yes / No) If not, why not? (text field)

M 15 Do you feel sufficiently informed about climate change after using WAVE? (Yes / No) If not, why not? (text field)

M 16 Does the platform provide easy understandable information to engage in the online discussion of the topics? (Yes / No) If not, why not? (text field)

M 17 Would you be interested to start or participate in another discussion (apart from the environment) via the WAVE platform? (Yes / No) 
Table 1. (Continued)

\begin{tabular}{l|c}
\hline \multicolumn{2}{c}{ Contact and sustainability } \\
\hline M 18 & How did you learn about the WAVE platform? (Invitation / Internet / \\
WAVE newsletter / WAVE Facebook group or Twitter feeds / Personal \\
Contact / Conference or workshop / Other) \\
How often did you visit the WAVE platform? (Never / I time / 2 times \\
/ 3-4 times / 5 times or more) \\
How often did you contribute, e.g. by posting, rating, participating in an \\
opinion poll, etc.? (Never / 1 time / 2 times / 3-4 times / 5 times or more) \\
Please indicate on the scale the extent to which you found this site of \\
interest (Found it extremely interesting / High interest / Neutral / Low \\
interest / Not interesting at all) \\
Would you consider participating again after the project terminates? \\
M Yes / No) \\
Would you recommend this platform to other people? (Yes / No) \\
Is this the first time you are using an eParticipation platform? (Yes / I \\
have used one eParticipation platform before / I have used several \\
eParticipation platforms before / I am a regular user) \\
Do you consider registration an obstacle for use? (Yes / No)
\end{tabular}

\section{$4 \quad$ Results}

Overall, 319 filled-in questionnaires were gathered. Respondents originate from eleven EU countries - Belgium, Czech Republic, Denmark, Finland, France, Greece, Lithuania, the Netherlands, Poland, Slovakia and the UK - with the majority coming from Lithuania (56.4\%) and France (39.2\%). 54.8\% of respondents were male and $45.2 \%$ female. Most respondents are in their twenties $(61.8 \%)$ and thirties $(26.3 \%)$; $6.3 \%$ are over forty, $2.5 \%$ are over fifty and only $0.3 \%$ over sixty years old; $2.8 \%$ are under twenty years old. Most respondents are of higher education $(64.3 \%) ; 32.6 \%$ hold a secondary degree and only $3.1 \%$ are of primary education. $1.6 \%$ and $6.6 \%$ respectively develop and implement policies as their primary job, whereas $2.2 \%$ are researchers or consultants for policy makers. We also had $8.2 \%$ teachers/trainers and another $8.2 \%$ media professionals. Regarding familiarisation with technology, most respondents reported basic and advanced internet skills $(38.3 \%$ and $45.9 \%$ respectively), $5.7 \%$ reported professional internet skills and $10.1 \%$ no internet skills.

Tool and Technology Axis. Most respondents found the AV tool fairly easy to use $(59.6 \%$ ), whereas $27 \%$ found it not that easy to use, $11.6 \%$ very easy to use and only $1.9 \%$ reported the tool as very difficult to use. $67.4 \%$ reported no confusion in the AV tool's operation. However, the rest $32.6 \%$ reported different elements that caused them confusion: they found the argument map difficult to understand and difficult to add new elements at as they did not easily grasp the different idea types (e.g. issue, position, argument) and their conceptual differences. Moreover, when the map was too crowded with ideas it became difficult for users to read the ideas and navigate through them (highlighting thus the important role of moderation). Also, users were confused by the lack of 'forum-like' functions like general quick responses and comments. Users also reported the best and worst features of the platform according to 
their own opinion; answers have been partly contradicting. Users reported the argument map, the selected topic and debates and the ability to create polls and groups as best features. They liked viewing the arguments per topic in a structured way (for and against arguments separated) and they liked that the overall interface was colourful, simple and playful. On the other hand, users also reported the argument map as one of the worst features; they found it complicated at least in the beginning and difficult to navigate and participate to, as it is difficult ensuring that contributed ideas are not similar to the ones already appearing on the map. Also, users did not like the lack of social features (e.g. linking with friends). The aspect of authorship is another contradicting point as some users did not like the publicly available activity list, which depicts latest actions and actor's user name, whereas other users reported that they would like to see more authorship details per debate idea.

Process Axis. Nearly all respondents (95.6\%) agreed that the platform does help them to better understand the issues under discussion. More specifically, users reported that the AV platform mostly helps to:

- Express opinions (48.7\%)

- Make informed decisions $(33 \%)$

- Measure public opinion $(31.35 \%)$

- Engage with peers and form communities (29.5\%)

- Understand complex legislation $(25.7 \%)$

- Increase participation in the democratic process $(17.9 \%)$

Considering that this was the only multiple-answer metric, the percentage results are too low implying a high dispersion among answers. Regarding the kind of feedback they would like to receive, most users referred to summaries of debates, new ideas and new information, and statistical data especially in regard to the ones they already contributed to (e.g. new additions to the map the user contributed to, poll results of the polls the user participated in). They would like to see more network creation options (e.g. suggesting people with same ideas) and new thematic within the environment topic but also beyond. Of course, many users mentioned that they would like to get information whether the opinions and ideas of the map have contributed to decision making, if some of them have been actually implemented and in what ways.

Topic Axis. Users' vast majority (94.7\%) found interesting the climate change topic for this platform. $92.8 \%$ reported that the platform provides easy and understandable information for climate change in order to engage them in the online discussion, and $87.2 \%$ feel sufficiently informed about climate change after using the AV platform. However, users also commented that climate change already receives broad attention from other information sources (e.g. the media). For this reason some users felt that they were already sufficiently informed before using the platform and that more information and more discussion online is needed. A few users also mentioned that they would like to see more factual information and sources as it is difficult to fully trust the information of a platform that is collectively shaped by users. Nevertheless, $88.7 \%$ of respondents said that they would be interested in participating in another discussion apart from climate change through this platform.

Contact and Sustainability Axis. Users reported that they heard about the platform through their personal contacts $(23.8 \%)$, a friend invitation $(18.2 \%)$, a conference or 
workshop (15.7\%), and via the internet (15.4\%). Most respondents visited the platform quite a few times; $30.1 \%$ paid one visit, $20.7 \%$ two visits, $15.4 \%$ three to four visits, and $28.2 \%$ five visits or more. The rest $5.6 \%$ reported other answers. Roughly $1 / 4$ (23.2\%) of respondents never contributed to the platform, another $1 / 4$ $(25.7 \%)$ contributed once and the rest $1 / 2$ contributed two times or more (17.2\% two times, $15.7 \% 3$ to 4 times, and $18.2 \%$ fives times or more).14.7\% of respondents found the website extremely interesting, $49.8 \%$ found it of high interest, $7.5 \%$ of low interest and only $1.3 \%$ not interesting at all; $26.7 \%$ had a neutral positioning. However, $87.2 \%$ stated that they would participate again after the project terminates and another $91.2 \%$ would recommend it to other people. For the majority of users $(62.1 \%)$ this has been the first time they used an eParticipation platform; $24.5 \%$ had previously used another platform, $10.2 \%$ have previously used several eParticipation platforms and only $3.2 \%$ are regular users of eParticipation platforms. Finally, most users $(62.7 \%)$ do not see registration as an obstacle for use, although the rest $37.3 \%$ is still a high percentage that can not be easily neglected.

Correlation Analysis. Applying correlation analysis on the gathered input of the evaluation survey, we were able to deepen into users' feedback. Correlation analysis has been performed in SPSS 19 software; all correlations reported here are according to Spearman' rho correlation testing significant at the 0.01 level (2-tailed).

As far as users' demographic data is concerned, correlation testing revealed that the older the users the more interesting they found the platform $\left(.152^{* *}\right)$ and that the more educated the users the easier they found the platform $\left(.201^{* *}\right)$. Moreover, higher internet experience on behalf of users accounts for highest frequency of visits and highest frequency of contributions to the platform (.382** and $.302 * *$ respectively).

Interesting results were also revealed as regards users' interaction with the platform and sustainability: users who frequently used the platform reported less confusion in its usage $(.157 * *)$ and a higher probability of frequent contributions $(.596 * *)$.

Users who did not regard the registration process as an obstacle for use, provided more frequent contributions to the platform $\left(.195^{* *}\right)$ and found the site to be of higher interest $(.163 * *)$ than the users who were negatively positioned to registering.

Users who found interesting the site and the topic and reported that they will come back to the site after project termination, also reported that they would recommend to other people $\left(.310^{* *}, .321^{* *}\right.$ and $.510^{* *}$ respectively). The same attitude towards further recommending the site comes from users who reported that the platform helps to understand the issues under discussion $\left(.366^{* *}\right)$ and that they feel sufficiently informed after using the platform $\left(.311^{* *}\right)$. Additionally, users who believe that the platform helps to understand the issues under discussion $\left(.284^{* *}\right)$ and to engage with peers and form communities $(.187 * *)$ reported that they would come back to the platform after the project ends.

Respondents who are frequent users of eParticipation websites seem to agree more that the platform contributes to understanding complex legislation $(.209 * *)$, to making informed decisions $\left(.204^{* *}\right)$, and to increasing participation in the democratic process $\left(.206^{* *}\right)$.

Correlation analysis showed strong relations between all metrics of the Topic axis as well as between these and metrics M21 and M22 ("the extent to which the site is interesting" and "whether they would participate again after the project terminates"). These correlations are depicted in Table 2. On the contrary, only loose correlations 
are observed between the metrics of the Process axis, as depicted in Table 3. This strengthens the observation mentioned previously for a high dispersion among users' answers in Metric 12.

Table 2. Correlation results for the metrics of the Topic axis. (M14: climate change interesting, M15: sufficiently informed, M16: understandable information to engage, M17: interested to participate in another discussion, M21: site interesting, M22: come back after termination).

\begin{tabular}{|c|c|c|c|c|c|c|c|}
\hline & & M14 & M15 & M16 & M17 & M21 & M22 \\
\hline M14 & $\begin{array}{l}\text { Correl. Coeff. } \\
\text { Sig. (2-tailed) }\end{array}$ & 1,000 & $\begin{array}{r}326^{* *} \\
, 000\end{array}$ & $\begin{array}{r}, 204^{* *} \\
, 000\end{array}$ & $\begin{array}{r}, 268^{* *} \\
, 000\end{array}$ & $\begin{array}{r}, 291^{* *} \\
, 000\end{array}$ & $\begin{array}{r}326^{* *} \\
, 000\end{array}$ \\
\hline M15 & $\begin{array}{l}\text { Correl. Coeff. } \\
\text { Sig. (2-tailed) }\end{array}$ & $\begin{array}{r}, 326^{* * *} \\
, 000 \\
\end{array}$ & 1,000 & $\begin{array}{r}, 255^{* * *} \\
, 000 \\
\end{array}$ & $\begin{array}{r}159^{* *} \\
, 004 \\
\end{array}$ & $\begin{array}{r}310^{* * *} \\
, 000 \\
\end{array}$ & $\begin{array}{r}, 272^{* * *} \\
, 000 \\
\end{array}$ \\
\hline M16 & $\begin{array}{l}\text { Correl. Coeff. } \\
\text { Sig. (2-tailed) }\end{array}$ & $\begin{array}{r}, 204^{* *} \\
, 000\end{array}$ & $\begin{array}{r}, 255^{* *} \\
, 000 \\
\end{array}$ & 1,000 & $\begin{array}{r}169^{* *} \\
, 003 \\
\end{array}$ & $\begin{array}{r}186^{* *} \\
, 001 \\
\end{array}$ & $\begin{array}{r}183^{* *} \\
, 001 \\
\end{array}$ \\
\hline M17 & $\begin{array}{l}\text { Correl. Coeff. } \\
\text { Sig. (2-tailed) }\end{array}$ & $\begin{array}{r}, 268^{* * *} \\
, 000 \\
\end{array}$ & $\begin{array}{r}159^{* * *} \\
, 004 \\
\end{array}$ & $\begin{array}{r}169^{* * *} \\
, 003 \\
\end{array}$ & 1,000 & $\begin{array}{r}, 251^{* * *} \\
, 000 \\
\end{array}$ & $\begin{array}{r}, 277^{* * *} \\
, 000 \\
\end{array}$ \\
\hline M21 & $\begin{array}{l}\text { Correl. Coeff. } \\
\text { Sig. (2-tailed) }\end{array}$ & $\begin{array}{r}, 291^{\text {*** }} \\
, 000 \\
\end{array}$ & $\begin{array}{r}310^{* * *} \\
, 000 \\
\end{array}$ & $\begin{array}{r}186^{* * *} \\
, 001 \\
\end{array}$ & $\begin{array}{r}, 251^{* * *} \\
, 000 \\
\end{array}$ & 1,000 & $\begin{array}{r}, 331^{* * *} \\
, 000 \\
\end{array}$ \\
\hline M22 & $\begin{array}{l}\text { Correl. Coeff. } \\
\text { Sig. (2-tailed) }\end{array}$ & $\begin{array}{l}, 326^{* * *} \\
, 000\end{array}$ & $\begin{array}{r}, 272^{* * *} \\
, 000\end{array}$ & $\begin{array}{r}183^{* * *} \\
, 001\end{array}$ & $\begin{array}{r}, 277^{* *} \\
, 000\end{array}$ & $\begin{array}{r}331^{* * *} \\
, 000\end{array}$ & 1,000 \\
\hline
\end{tabular}

**. Correlation is significant at the 0.01 level (2-tailed).

Table 3. Correlation results for the metrics of the Process axis. (M11: understand issues under discussion, M12a: complex legislation, M12b: express opinions, M12c: measure public opinion, M12d: engage with peers and form communities, M12e: increase participation, M12f: informed decisions)

\begin{tabular}{|ll|r|r|r|r|r|r|r|}
\hline & & M11 & M12a & M12b & M12c & M12d & M12e & M12f \\
\hline M11 & Cor. Coeff. & 1,000 &,- 014 &,- 128 &, 013 &, 105 &,- 060 &, 020 \\
& Sig.(2-tail) & \multicolumn{1}{|c|}{} &, 803 &, 022 &, 820 &, 061 &, 286 &, 718 \\
\hline M12a & Cor. Coeff. &,- 014 & 1,000 &,- 129 &, 128 &, 108 &, 156 &, $228^{* * *}$ \\
& Sig.(2-tail) &, 803 &. &, 021 &, 022 &, 055 &, 005 &, 000 \\
\hline M12b & Cor. Coeff. &,- 128 &,- 129 & 1,000 &,- 227 &,- 101 &, 086 &, 054 \\
& Sig.(2-tail) &, 022 &, 021 &. &, 000 &, 071 &, 128 &, 342 \\
\hline M12c & Cor. Coeff. &, 013 &, 128 &,$- 227^{* *}$ & 1,000 &,- 051 &, 143 &,- 043 \\
& Sig.(2-tail) &, 820 &, 022 &, 000 &. &, 360 &, 010 &, 440 \\
\hline M12d & Cor. Coeff. &, 105 &, 108 &,- 101 &,- 051 & 1,000 &, 058 &, 034 \\
& Sig.(2-tail) &, 061 &, 055 &, 071 &, 360 &. &, 306 &, 549 \\
\hline M12e & Cor. Coeff. &,- 060 &, 156 &, 086 &, 143 &, 058 & 1,000 &, 265 \\
& Sig.(2-tail) &, 286 &, 005 &, 128 &, 010 &, 306 &. &, 000 \\
\hline M12f & Cor. Coeff. &, 020 &, 228 &, 054 &,- 043 &, 034 &, 265 & 1,000 \\
& Sig.(2-tail) &, 718 &, 000 &, 342 &, 440 &, 549 &, 000 &. \\
\hline
\end{tabular}

*. Correlation is significant at the 0.05 level (2-tailed).

**. Correlation is significant at the 0.01 level (2-tailed). 


\section{Discussion}

It is worth commencing this discussion with the observation that the sample of our questionnaire evaluation has been a relatively 'good' one, skewed towards producing positive results for the AV platform. In specific, our sample consists mainly of young, educated and computer-literate people; $90 \%$ of respondents are under forty years old and have at least basic internet skills, and $64 \%$ have a higher education degree. Moreover, most respondents have been active users of the platform; 64\% visited the platform two times or more, and $77 \%$ contributed at least once to the platform. As shown also from correlation testing, age, education and internet literacy play a significant role in users' perception of platform's interest and easiness and in user's frequency of interactions with the platform. We are therefore inclined to believe that evaluation results stemming from this ideal population sample must be relatively skewed towards the positive side of the metrics as opposed to potential results from a representative sample of the whole population.

Having said that, we could argue that received feedback has been very positive. Most users found the platform and topic interesting and understandable, and they felt that the platform contributed to their sufficient informing and better understanding of climate change. Additionally, most users stated that they would use the platform again in the future regardless of topic, and that they would recommend it to other people.

However, negative feedback has also been received, mostly things that frustrated users and suggestions for improvement. A core issue is that users experienced problems with the overall philosophy of structured argumentation. It seems that navigating an argumentation map and having to contribute in terms of positions, arguments, etc. is clearly much more difficult than forum-like participation requiring extra time and attention from users. And it gets more difficult in the case that "too much" participation occurs; heavily loaded argumentation maps become unclear and tiring to read. We believe that such difficulties are inherent in all AV tools, not only the specific one used in this platform (Debategraph), thus the issue is raised whether AV tools can be actually and efficiently massively utilised.

Ambiguous feedback has been received from users regarding authorship of contributions. Similarly to other AV tools, the platform does not provide author details per map element. It does, however, provide a stream of latest actions and actors. Users' feedback suggests as a weak point of the platform the lack of authorship details; this causes to citizens a feeling of non-trustworthy debate information. Therefore, they would prefer to know the author of each information piece and to have more factual information offered. However, there are also users who were against publicising users' authorship details even in the latest action stream. We believe this is directly related to users' feedback on whether registration to the platform is considered as a barrier for participation; it seems that many users regard registration as a barrier and correlation analysis also showed that users who found the site interesting and did contribute frequently were the ones who did not regard registration as an obstacle. In this trade-off between transparency and privacy it is certainly not clear from the received feedback which should be the most preferred solution for such a platform. 
Additionally, users' feedback has shown how much they value relationship and community building. Although the group function of the platform was appreciated, users seek for even more networking options and forming of relationships online. It is not clear however, to what degree this functionality is really needed or whether it is requested due to the users' being accustomed to see social features in most of the online platform they use.

Furthermore, users want to receive feedback and updates from such an eParticipation platform such as debate summaries, new opinions and ideas. Of course, and similarly to any other eParticipation platform, feedback should also include information whether the opinions and ideas of the map have contributed to decision making and even better if some of them have been actually implemented and in what ways. However, it seems that users will not be easily satisfied by receiving any type of mass updates and feedback. They placed emphasis on personalised type of feedback; for example receiving updates only on the topics they had shown interest at (i.e. they have contributed to).

\section{Conclusion}

In this paper we present citizens' evaluation of an AV platform utilised for eParticipation. The evaluation was conducted in four different axes: platform's usability and ease of use; position in the policy making process; selection of topic debated; and potential for future use. Overall, user evaluation has been very positive withstanding the fact that the respondents have been a relatively 'ideal' sample: young, educated, computer-literate persons. Nevertheless, user evaluation results also suggest that there is room for improving the usability of the AV tool.

In this paper we based our evaluation in a particular AV platform, however we believe that the results can, to some extent, apply to other AV platforms and tools as well. This is due to the maturity and stability of the selected AV tool (Debategraph) which may also be regarded as a fair representative sample of AV tools. Furthermore, it is also due to the fact that our evaluation methodology put emphasis on general issues relevant to $\mathrm{AV}$ as opposed to specific platform characteristics. Nevertheless, we should highlight that the evaluation results are not directly applicable to all AV tools and to all different contexts where such tools may be used.

Acknowledgement. Work presented in this paper was performed within WAVE, a project partially funded by European Commission under the eParticipation Preparatory Action programme. The authors would like to acknowledge the support of all consortium partners.

\section{References}

1. Schyns, P., Koop, C.: Political Distrust and Social Capital in Europe and the USA. Social Indicators Research 96(1), 145-167 (2010)

2. European Commission, Better Regulation - Simply explained, http: / / ec.europa.eu/governance/better_regulation/ documents/brochure/br_brochure_en.pdf 
3. European Commission, Smart Regulation in the European Union, COM, 543 final (2010)

4. Panopoulou, E., Tambouris, E., Tarabanis, K.: eParticipation initiatives: How is Europe progressing? European Journal of ePractice No. European Journal of ePractice (7), 15-26 (2009)

5. DEMO-net Deliverable D5.2: eParticipation: The potential of new and emerging technologies (2007)

6. Shum, S.B.: Cohere: Towards web 2.0 argumentation. In: Hunter, A. (ed.) Proceedings of the 2nd International Conference on Computational Models of Argument (COMMA). IOS Press, Amsterdam (2008)

7. Van den Braak, S.W., Vreeswijk, G.A.W.: AVER: Argument visualization for evidential reasoning. In: Legal Knowledge and Information Systems, JURIX 2006: The Nineteenth Annual Conference, Amsterdam, The Netherlands, pp. 151-156 (2006)

8. Atkinson, K., Cartwright, D.: Political Engagement through Tools for Argumentation. In: Proceedings of COMMA 2008, pp. 116-127 (2008)

9. Lee, D., Menda, Y.P., Price, D., Tambouris, E., Peristeras, V., Tarabanis, K.: Platforms To Facilitate Online Political Debates: The Wave Platform. In: Chappelet, J.L., Glassey, O., Janssen, M., Macintosh, A., Scholl, J., Tambouris, E., Wimmer, M.A. (eds.) Electronic Government and Electronic Participation: Joint Proceedings of Ongoing Research and Projects of IFIP EGOV and ePart 2010, Trauner Duck, pp. 303-310 (2010)

10. Rowe, G., Frewer, L.J.: Public Participation Methods: A framework for Evaluation. Science Technology Human Values 25(3) (2000)

11. DEMO-net D13.3 DEMO-net booklet: eParticipation Evaluation and Impact (2008)

12. MOMENTUM Deliverable D2.5: e-participation projects evaluation methodology (2008)

13. Loukis, E., Xenakis, A., Charalabidis, Y.: An evaluation framework for e-participation in parliaments. International Journal of Electronic Governance 3(1), 25-47 (2010)

14. Henderson, M., Hogarth, F., Jeans, D.: Evaluation Framework for Assessing E-Democracy Policy. Encyclopedia of Digital Government (2007)

15. Whyte, A., Macintosh, A.: Analysis and evaluation of e-consultations. e-Service Journal 2(1), 9-34 (2003)

16. European eParticipation Deliverable 4.1b Framework for eParticipation Good Practice (2008) 